\title{
Microstructure and Wear Resistance of Spray-Formed Supermartensitic Stainless Steel
}

\author{
Guilherme Zepon $^{\mathrm{a} *}$, Claudio Shyinti Kiminami ${ }^{\mathrm{b}}$,Walter José Botta Filho ${ }^{\mathrm{b}}$, Claudemiro Bolfarini $^{\mathrm{b}}$ \\ ${ }^{a}$ Postgraduate Program in Science and Materials Engineering, \\ Federal University of São Carlos - UFSCar, São Carlos, SP, Brazil \\ ${ }^{\mathrm{b}}$ Department of Materials Engineering, Federal University of São Carlos - UFSCar, \\ São Carlos, SP, Brazil
}

Received: November 1, 2012; Revised: January 8, 2013

\begin{abstract}
Since the early 90's the oil industry has been encouraging the development of corrosion and wear resistant alloys for onshore and offshore pipeline applications. In this context supermartensitic stainless steel was introduced to replace the more expensive duplex stainless steel for tubing applications. Despite the outstanding corrosion resistance of stainless steels, their wear resistance is of concern. Some authors reported obtaining material processed by spray forming, such as ferritic stainless steel, superduplex stainless steel modified with boron, and iron-based amorphous alloys, which presented high wear resistance while maintaining the corrosion performance ${ }^{1,2}$. The addition of boron to iron-based alloys promotes the formation of hard boride particles $\left(\mathrm{M}_{2} \mathrm{~B}\right.$ type $)$ which improve their wear resistances ${ }^{3-9}$. This work aimed to study the microstructure and wear resistance of supermartensitic stainless steel modified with $0.3 \mathrm{wt}$. (\%) and $0.7 \mathrm{wt}$. (\%) processed by spray forming (SF-SMSS $0.3 \% \mathrm{~B}$ and SF-SMSS $0.7 \% \mathrm{~B}$, respectively). These boron contents were selected in order to improve the wear resistance of supermartensitic stainless steel through the formation of uniformly distributed borides maintaining the characteristics of the corrosion resistant matrix. SF-SMSS $0.7 \% \mathrm{~B}$ presents an abrasive wear resistance considerably higher than spray-formed supermartensitic stainless steel without boron addition (SF-SMSS).
\end{abstract}

Keywords: supermartensitic stainless steel, spray forming, wear resistance

\section{Introduction}

The aggressive environment encountered in oil exploration platforms subjects parts of the equipment such as valves, pumps and pipelines to extreme corrosion and wear conditions. Based on this, the oil industries have been encouraging the development of corrosion and wear resistant alloys. In the last decade the spray forming process has been largely used in the development of wear resistant alloys $\mathrm{s}^{1,2,10,11}$. The spray forming process consists of an inert gas atomization of a liquid metal stream into variously sized droplets which are then propelled from the atomizer by the fast-flowing atomization gas. The subsequent deposition of these droplets, which are a mixture of solid, liquid and partially solidified particles, onto a substrate forms an almost totally dense deposit. By continuous movement of the substrate relative to the atomizer as the atomization proceeds, large deposits can be produced on a variety of geometries, including discs, tubes and plates. Spray forming presents features of rapid solidification techniques and thus the resulting microstructures of the deposits are macrosegregation-free with fine uniform equiaxed grains and fine uniformly distributed primary and secondary phase precipitates $^{12,13}$. Some authors reported that alloys, such as high chromium white cast irons, produced by spray forming present superior sliding and abrasive wear resistance than the same alloys produced by conventional casting, due to the refined microstructures and homogeneously distributed

*e-mail: guizepon@yahoo.com.br carbides obtained by the spray forming process ${ }^{10,11,14,15}$. In recent years, some works have reported the development of new wear resistant alloys, such as ferritic stainless steel and iron-based amorphous alloys, processed by spray forming ${ }^{1,2}$.

Many authors reported the use of boron to improve the wear resistance of high chromium cast irons by precipitation of primary borides such as $\mathrm{M}_{2} \mathrm{~B}(\mathrm{M}=\mathrm{Fe}, \mathrm{Cr}, \mathrm{Mo})$, given that boron solubility in ferrous alloys is very small $(0.0005-0.008 \text { at.\% })^{3,7}$. In a recent work, Beraldo et al. ${ }^{1}$ reported obtaining spray-formed superduplex stainless steel modified with $3.7 \mathrm{wt}$. (\%) of boron which presented higher wear resistance than the Cr-Co alloy Stellite 1016. In line with these reports, this work presents an evaluation of the wear resistance of supermartensitic stainless steel Fe-12Cr-5Ni-1Mo modified with small quantities of boron $(0.3$ wt. (\%) and 0.7 wt. (\%)) processed by spray forming. In order to obtain martensitic phase without $\delta$ ferrite, the maximum chromium content allowed for transformable steel has been determined to be around $13 \mathrm{wt} .(\%)^{16}$. Furthermore, it is well known that $10.5 \mathrm{wt}$. (\%) $\mathrm{Cr}$ is required to obtain passivity in stainless steels. The boron addition leads to the formation of borides, usually of the $\mathrm{M}_{2} \mathrm{~B}$ type, which reduces the chromium content of the matrix. Based on this, these low boron contents, when compared to the contents used by Beraldo et al. ${ }^{1}$ in superduplex stainless steel, were selected with a view to maintaining the chromium content of the steel matrix in the range of 10.5-13 wt. (\%). 


\section{Experimental Procedure}

This study involved three alloys based on the chemical composition of $12 \mathrm{Cr}-5 \mathrm{Ni}-1 \mathrm{Mo}$ supermartensitic stainless steel (SF-SMSS), with two of them being modified with 0.3 wt. (\%) and 0.7 wt. (\%) of boron (SF-SMSS 0.3\%B and SF-SMSS $0.7 \% \mathrm{~B}$, respectively). Commercial $316 \mathrm{~L}$ stainless steel, iron and commercially pure chromium and pure boron (Alfa Cesar, 99.5\%) were the raw materials used. In order to achieve the chemical composition of the SMSS, the $316 \mathrm{~L}$ stainless steel was diluted with commercially pure iron and adjusted with commercially pure chromium. Given that commercially available iron-boron alloys usually present high levels of carbon contents, pure boron was used to maintain the low carbon content in the alloys produced. Approximately $3.5 \mathrm{~kg}$ of each alloy were melted in a vacuum induction furnace under argon atmosphere and cast into $180 \mathrm{~mm}$-long, $70 \mathrm{~mm}$-diameter resin-bonded sand molds, resulting in three ingots which were subsequently spray-formed. The parameters used in the spray forming process were applied to all compositions studied, i.e., casting temperature of $1700^{\circ} \mathrm{C}$, nitrogen gas under $0.5 \mathrm{MPa}$ pressure as the atomizing gas and $365 \mathrm{~mm}$ flight distance. The alloys were deposited onto a rotating steel substrate of $250 \mathrm{~mm}$ diameter and $45 \mathrm{rpm}$ rotating speed. Details of the equipment used are described elsewhere ${ }^{17}$.

The resulting deposits were characterized by chemical analysis, using inductively coupled plasma atomic emission spectrometry-ICP-AES, the nitrogen content was determined by thermal conductivity difference and the carbon content was determined by direct combustion. The materials were analyzed by X-ray diffraction using $\mathrm{Cu}$ Koradiation (XRD) and their microstructures were characterized by scanning electron microscopy (SEM) using a PHILIPS XL30 Field Emission Gun Scanning Electron Microscope.

Rockwell $\mathrm{C}$ hardness was measured using a load of $150 \mathrm{~kg}$ with a diamond cone indenter. The three materials were subjected to abrasive wear tests using a homemade dry sand/rubber wheel apparatus, following procedure A of the ASTM G65-04 "Standard Test Method for Measuring Abrasion Using the Dry Sand/Rubber Wheel Apparatus".

\section{Results and Discussion}

\subsection{Chemical composition}

Table 1 shows the chemical composition of the alloys. All spray-formed materials present carbon content higher than conventional supermartensitic stainless steel $(<0.03$ wt. $(\%)$ ), but chromium, nickel and molybdenum contents are within the range of this class of steel.

\subsection{Microstructural characterization}

The spray-formed deposits were dense and homogeneous with a thickness of around $15 \mathrm{~mm}$, useful diameter of $125 \mathrm{~mm}$ and approximately $2 \mathrm{~kg}$ in weight. Figure 1 shows the XRD patterns of the three compositions studied. It is possible to observe in Figure 1a that all deposits present peaks related to the typical martensite of low carbon steels

Table 1. Chemical composition of the spray-formed supermartensitic stainless steel (SF-SMSS), with and without boron addition.

\begin{tabular}{lcccccccccc}
\hline \multirow{2}{*}{ Material } & \multicolumn{8}{c}{ Chemical composition (wt. (\%)) } \\
\cline { 2 - 11 } & $\mathbf{C}$ & $\mathbf{C r}$ & $\mathbf{N i}$ & $\mathbf{M o}$ & $\mathbf{S i}$ & $\mathbf{N}$ & $\mathbf{S}$ & $\mathbf{B}$ & Fe \\
\hline SF-SMSS & 0.056 & 10.98 & 4.98 & 0.97 & 0.04 & 0.029 & 0.16 & - & Bal. \\
SF-SMSS 0.3\%B & 0.054 & 10.45 & 4.15 & 1.07 & 0.08 & 0.016 & 0.13 & 0.26 & 0.68 & \\
SF-SMSS 0.7\%B & 0.067 & 10.99 & 4.95 & 0.96 & 0.10 & 0.017 & 0.13 & 0.13 \\
\hline
\end{tabular}

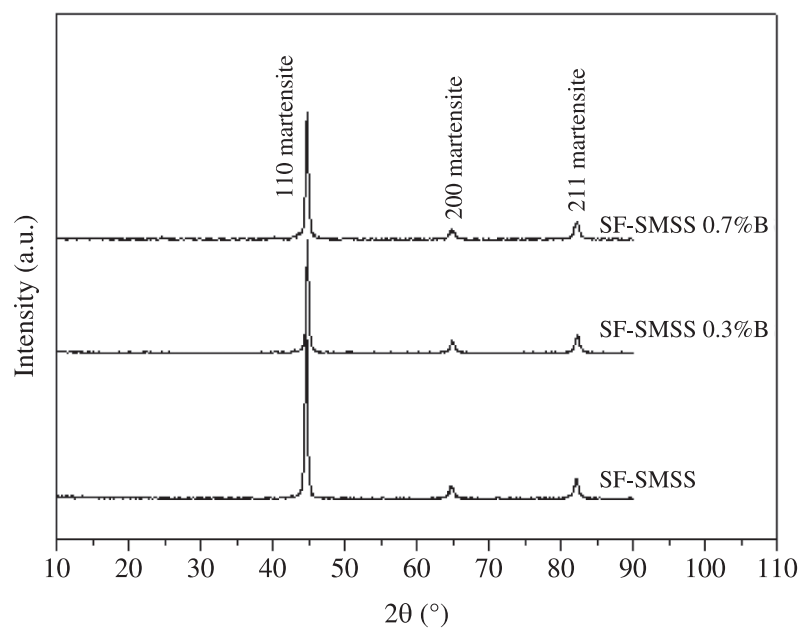

(a)

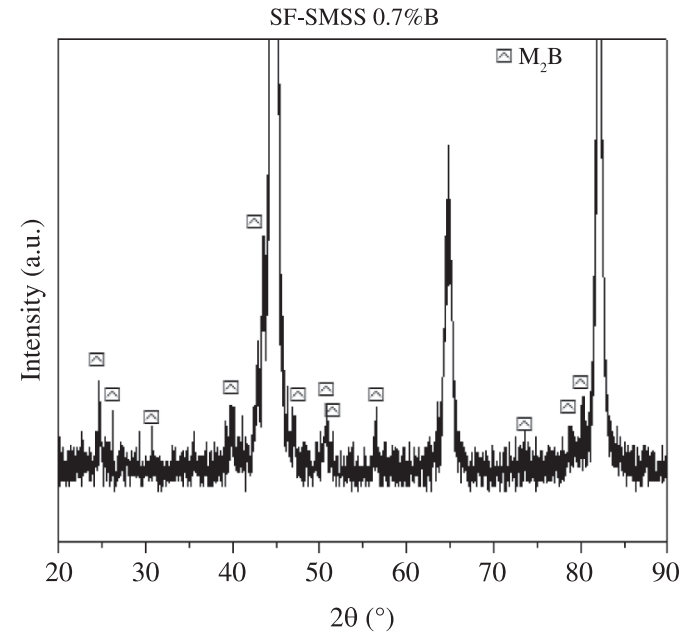

(b)

Figure 1. (a) XRD patterns of the three spray-formed supermartensitic stainless steels and (b) Zoom of the SF-SMSS 0.7\% B XRD pattern indicating the presence of the $\mathrm{M}_{2} \mathrm{~B}$ phase. 
with no evidence of retained austenite. Expanding the XRD pattern of the SF-SMSS $0.7 \%$ B, Figure $1 \mathrm{~b}$, it is possible to observe the presence of low intensity peaks of the $M_{2} B$ phase.

Figure 2. shows the microstructures of the three spray-formed materials obtained by SEM. The microstructure observed in the SF-SMSS, Figure 2a., is solely composed of low carbon martensite. The same phase is observed as matrixes of SF-SMSS $0.3 \% \mathrm{~B}$ and SF-SMSS $0.7 \%$ B microstructures (Figure 2b, c). However, precipitates of $M_{2} B$ phase are observed at the grain boundary of both microstructures. These borides were formed at high temperature in a solid state transformation restricting the austenite grain growth, resulting in a more refined microstructure. As expected, given that the boron supersaturation was higher in SF-SMSS $0.7 \% \mathrm{~B}$ than in SF-SMSS $0.3 \% \mathrm{~B}$, the amount of $\mathrm{M}_{2} \mathrm{~B}$ attained a higher level and the martensitic grain size was more refined in the former.

Chemical microanalyses were performed by EDS in each phase of the three materials and Table 2 summarizes the results obtained. The agreement between the chemical microanalysis and the chemical analysis performed by ICP-AES of the SF-SMSS reinforces the homogeneity of the deposit provided by the spray forming process. Another important aspect is that, for SF-SMSS $0.3 \% \mathrm{~B}$ and SF-SMSS $0.7 \% \mathrm{~B}$, both phases - martensitic matrix and $\mathrm{M}_{2} \mathrm{~B}$ - present chromium content greater than $10 \%$ (wt)., which might maintain the good corrosion properties of supermartensitic stainless steel.

It is important to point out that the addition of boron within the limits of this work has not altered the martensitic formation, a possibility that could occur since boron addition leading to the formation of borides could impoverish the chromium content of the matrix below the level necessary for its formation.

\subsection{Hardness and wear resistance}

The Rockwell C hardness of each spray-formed SMSS can be seen in Figure 3. It is important to note the relatively low wear resistance (compared to other classes of metal materials) of both Superduplex ASTM A890 and supermartensitic stainless steel without boron; however, among the various types of stainless steels, the latter presents one of the highest resistances to abrasive wear. The boron addition and formation of the $\mathrm{M}_{2} \mathrm{~B}$ borides increased the SF-SMSS hardness from 37 HRC to $40 \mathrm{HRC}$ for the SF-SMSS $0.3 \% \mathrm{~B}$ and to $47 \mathrm{HRC}$ for the SF-SMSS $0.7 \% \mathrm{~B}$. This increase in hardness was accompanied by an increase in wear resistance. It is possible to observe that SF-SMSS and SF-SMSS $0.3 \%$ B present volume losses of 45.29 and $43.24 \mathrm{~mm}^{3}$, respectively, lower than in conventional superduplex stainless steel, which

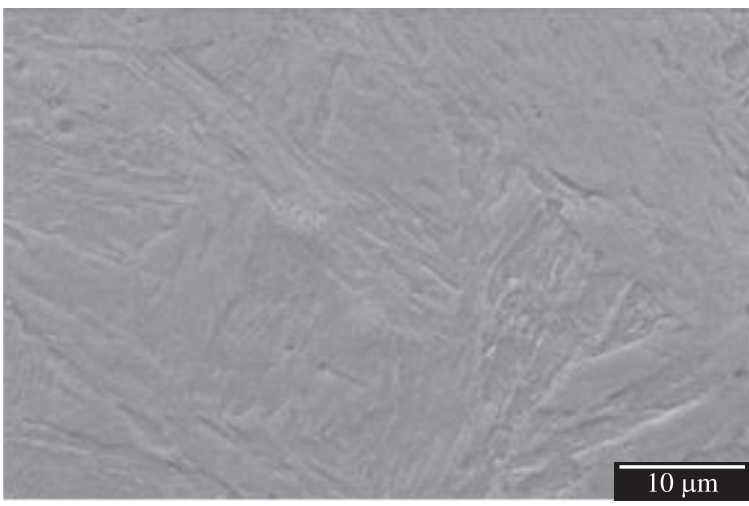

(a)

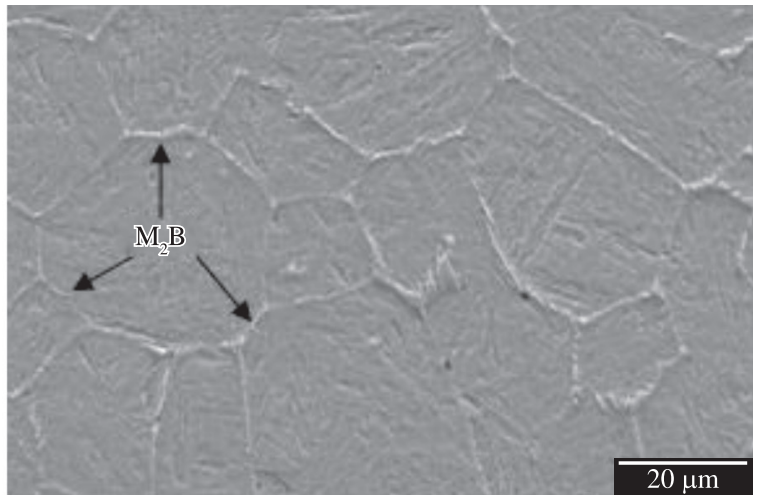

(b)

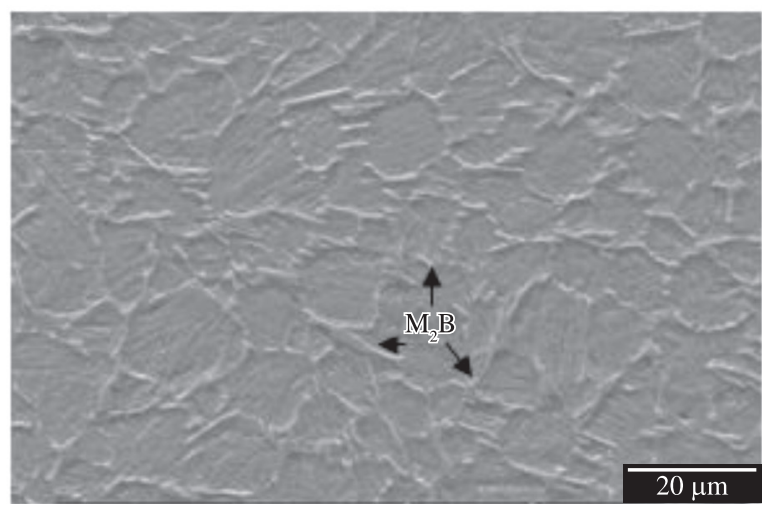

(c)

Figure 2. SEM images (secondary electrons) of the spray-formed (a) SF-SMSS, (b) SF-SMSS 0.3\% B and (c) SF-SMSS 0.7\% B. Etchant: Vilela. 
Table 2. Chemical composition of the different phases of each spray-formed alloy determined by EDS.

\begin{tabular}{|c|c|c|c|c|c|c|c|c|c|c|c|c|c|}
\hline \multirow{2}{*}{ Material } & \multirow{2}{*}{ Phase } & \multicolumn{6}{|c|}{ Chemical composition (wt. (\%)) } & \multicolumn{5}{|c|}{ Chemical composition (at. \%) } & \multirow[b]{2}{*}{ B } \\
\hline & & $\mathbf{F e}$ & $\mathbf{C r}$ & $\mathbf{N i}$ & Mo & Si & B & $\mathbf{F e}$ & $\mathrm{Cr}$ & $\mathbf{N i}$ & Mo & $\mathbf{S i}$ & \\
\hline SF-SMSS & Matrix & 82.85 & 11.03 & 4.89 & 0.98 & 0.26 & - & 82.49 & 11.80 & 4.63 & 0.57 & 0.51 & - \\
\hline SF-SMSS & Matrix & 84.47 & 10.27 & 4.25 & 0.75 & 0.23 & - & 84.10 & 10.98 & 4.03 & 0.43 & 0.46 & - \\
\hline $0.3 \% \mathrm{~B}$ & $\mathrm{M}_{2} \mathrm{~B}$ & 65.42 & 21.16 & 1.98 & 2.39 & 0.14 & 8.87 & 47.55 & 16.52 & 1.37 & 1.01 & 0.21 & $33.33 *$ \\
\hline SF-SMSS & Matrix & 83.31 & 10.75 & 5.10 & 0.54 & 0.19 & - & 82.98 & 11.50 & 4.83 & 0.31 & 0.38 & - \\
\hline $0.7 \% \mathrm{~B}$ & $\mathrm{M}_{2} \mathrm{~B}$ & 62.70 & 24.34 & 1.71 & 2.07 & 0.26 & 8.92 & 45.34 & 18.90 & 1.18 & 0.87 & 0.38 & $33.33 *$ \\
\hline
\end{tabular}

*Value calculated based on the $\mathrm{M}_{2} \mathrm{~B}$ stoichiometry.

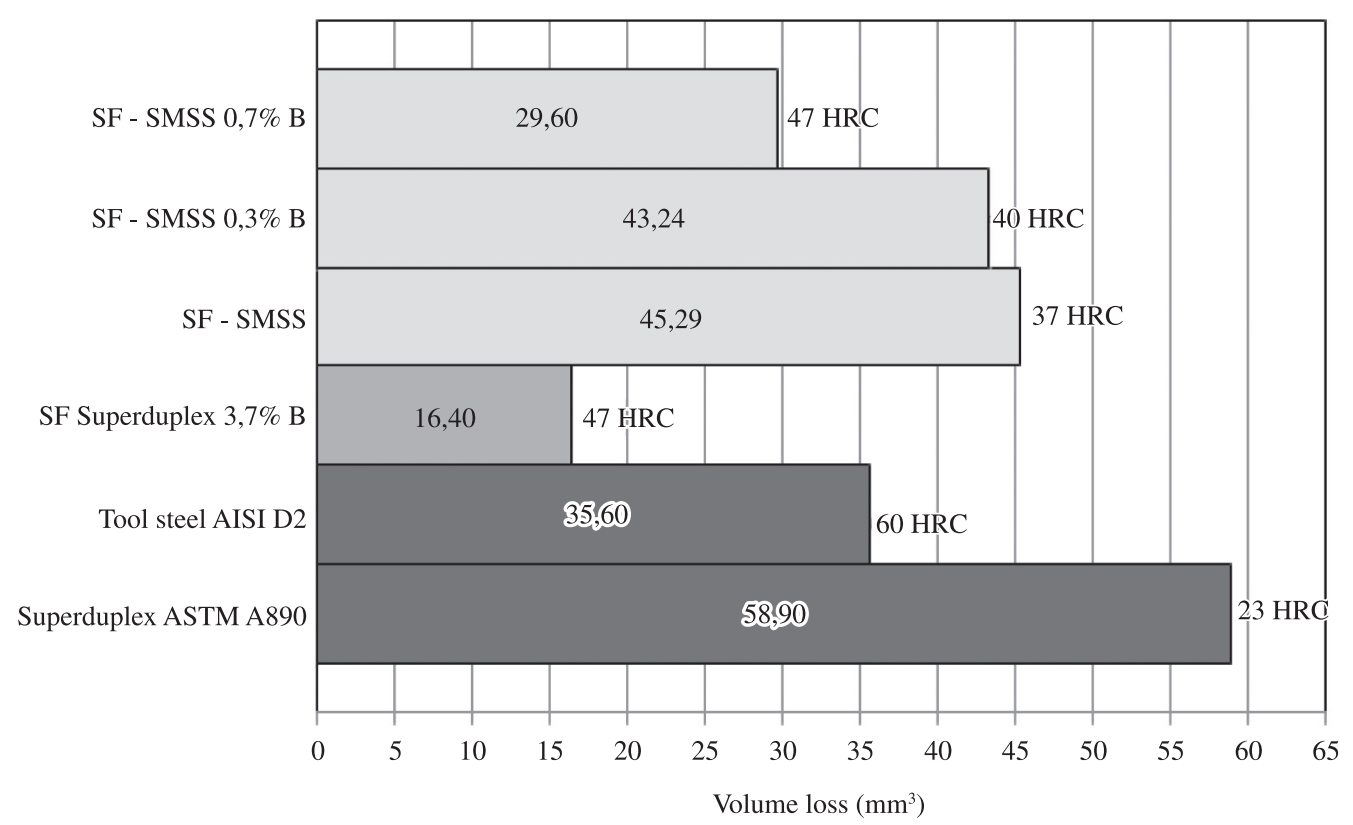

Figure 3. Hardness and abrasive wear resistance measured by sand/rubber wheel test - ASTM G65-04. (SF = Spray-formed).

presents lower hardness; however, their wear resistances are poor when compared to alloys of high hardness. On the other hand, the volume loss of SF-SMSS $0.7 \% \mathrm{~B}$ was $17 \%$ lower than AISI D2 tool steel with $60 \mathrm{HRC}$. This result can be attributed to a microstructure composed of a ductile martensitic matrix which anchors the hard particles of $\mathrm{M}_{2} \mathrm{~B}$ improving the wear resistance of SF-SMSS $0.7 \% \mathrm{~B}$. Nevertheless, the wear resistance of SF-SMSS $0.7 \% \mathrm{~B}$ is still lower than that presented by spray-formed superduplex stainless steel modified with $3.7 \%$ B produced by Beraldo et al. ${ }^{~}$.

The results of the wear test must be discussed in terms of hardness, type of matrix, size/distribution of borides. It is possible to observe in Figure 3 that although the hardness of SF-SMSS $0.7 \% \mathrm{~B}$ and superduplex with $3.7 \% \mathrm{~B}$ are the same, the wear resistance of the latter is considerably higher. The microstructure of the superduplex with $3.7 \% \mathrm{~B}$ presented by Beraldo et al. ${ }^{1}$ is composed of almost $40 \mathrm{vol} . \%$ of primary borides in a very soft austenitic/ferritic matrix (22 HRC) while the microstructure SF-SMSS $0.7 \% \mathrm{~B}$ is composed of less than $10 \mathrm{vol} \%$ of interconnected secondary borides that involve the harder martensitic matrix (37 HRC) which results in both materials with ultimately the same hardness. Tabrett et al. ${ }^{18}$, in their work on wear resistance of high chromium cast irons, showed that the ratio of abrasive grit size to the mean free distance of the matrix (RAM) can give an idea of the protection of the matrix offered by the carbides present in those materials. Fulcher et al. ${ }^{19}$ showed that if the RAM is large, i.e., if the distance between the hard particles is small, the carbides protect the matrix against wear and the matrix provides mechanical support to the carbides. When the RAM is small, i.e., when the distance between the hard particles is large, the wear of the matrix is more pronounced and determines the rate at which carbides become unsupported and liable to fracture. This could explain the better wear resistance of superduplex with $3.7 \% \mathrm{~B}$, given that its volume fraction of borides is considerably higher than SF-SMSS $0.7 \% \mathrm{~B}$, this implies that the distance between the borides in superduplex with $3.7 \% \mathrm{~B}$ is smaller than the distance between the borides in SF-SMSS $0.7 \% \mathrm{~B}$, in other words the RAM of superduplex with $3.7 \% \mathrm{~B}$ is considerable larger than that observed 
in SF-SMSS $0.7 \% \mathrm{~B}$, which increases the abrasive wear resistance of the former.

\section{Conclusions}

It was possible to produce dense deposits of supermartensitic stainless steel with high chemical and microstructural homogeneity by spray-forming. Boron addition in the composition of supermartensitic stainless steel led to solid state precipitation of $\mathrm{M}_{2} \mathrm{~B}$ borides in the austenite grain boundary, resulting in a refined martensitic grain size and increased hardness and wear resistance.

\section{References}

1. Beraldo LG. Avaliação da resistência ao desgaste deaços inoxidáveis conformados por spray. [Dissertação]. São Carlos: Universidade Federal de São Carlos; 2011.

2. Melle A. Produção e caracterização de recobrimentos de aço empregando a liga amorfizável $\mathrm{Fe}-\mathrm{Cr}$ - $\mathrm{Nb}$ - $\mathrm{B}$. [Dissertação]. São Carlos: Universidade Federal de São Carlos; 2012.

3. Liu Z, Chen X, Li Y and Hu K. High Boron Iron-Based Alloy and Its Modification. Journal of Iron and Steel Research. 2009; 16(3):37-54. http://dx.doi.org/10.1016/S1006706X(09)60041-8

4. Huang $\mathrm{Z}$, Xing $\mathrm{J}$ and Guo $\mathrm{C}$. Improving fracture toughness and hardness of $\mathrm{Fe}_{2} \mathrm{~B}$ in high boron white cast iron by chromium addition. Materials \& Design. 2010; 31(6):3084-3089. http:// dx.doi.org/10.1016/j.matdes.2010.01.003

5. Kim JH, Ko KH, Noh SD, Kim GG and Kim SJ. The effect of boron on the abrasive wear behavior of austenitic Fe-based hardfacing alloys. Wear. 2009; 267(9-10):1415-1419. http:// dx.doi.org/10.1016/j.wear.2009.03.017

6. Liu Z, Li Y, Chen X and Hu K. Microstructure and mechanical properties of high boron white cast iron. Materials Science and Engineering: A. 2008; 486(1-2):112-116. http://dx.doi org/10.1016/j.msea.2007.10.017

7. Ma S, Xing J, Fu H, Gao Y and Zhang J. Microstructure and crystallography of borides and secondary precipitation in 18 wt. $\%$ Cr -4 wt. \%Ni- 1wt.\%Mo -3.5 wt.\% B-0,27 wt.\%C steel. Acta Materialia. 2012; 60:831-843. http://dx.doi.org/10.1016/j. actamat.2011.11.004

8. Naiheng MA, Qichang R and Qingde Z. Corrosion-abrasion wear resistance of $28 \% \mathrm{Cr}$ white cast iron containing boron. Wear. 1989; 132(2):347-359. http://dx.doi.org/10.1016/00431648(89)90083-5

9. Yoo JW, Lee SH, Yoon CS and Kim SJ. The effect of boron on the wear behavior of iron-based hardfacing alloys for nuclear power plants valves. Journal of Nuclear Materials. 2006; 352(1-3):90-96. http://dx.doi.org/10.1016/j. jnucmat.2006.02.071

10. Matsuo TT, Kiminami CS, Fo WJB and Bolfarini C. Sliding wear of spray-formed high-chromium white cast iron alloys. Wear. 2005; 259(1-6):445-452. http://dx.doi.org/10.1016/j. wear.2005.01.021
SF-SMSS and SF-SMSS $0.3 \%$ B presented 37 and $40 \mathrm{HRC}$, respectively, and better wear resistance than the conventional superduplex stainless steel, whereas SF-SMSS 0.7\%B presented $47 \mathrm{HRC}$ and wear resistance higher than the 60 HRC AISI D2 tool steel.

\section{Acknowledgements}

We would like to thank the São Paulo Research Foundation (FAPESP) and PETROBRAS for their financial support for this study.

11. Kasama AH, Mourisco AJ, Kiminami CS, Fo WJB and Bolfarini C. Microstructure and wear resistance of spray formed high chromium white cast iron. Materials Science and Engineering A. 2004; 375-377):589-594. http://dx.doi. org/10.1016/j.msea.2003.10.093

12. Grant PS. Spray forming. Progress in Materials Science. 1995; 39(4-5):497-545. http://dx.doi. org/10.1016/0079-6425(95)00004-6

13. Kiminami CS, Botta WJ and Bolfarini C. Processing of glass former alloys by spray forming. Herstellung von Legierungen für Glasformen durch Sprühkompaktieren. Materialwissenschaft und Werkstofftechnik. 2010; 41(7):513-523. http://dx.doi. org/10.1002/mawe.201000637

14. Guo MLT, Chiang C and Tsao CYA. Microstructure and wear behavior of spray-formed and conventionally cast rolls of $18 \mathrm{Cr}-2.5 \mathrm{Mo}-\mathrm{Fe}$ alloy. Materials Science and Engineering A. 2002; 326:1-10. http://dx.doi.org/10.1016/ S0921-5093(01)01434-4

15. Hanlon DN, Rainforth W M and Sellars CM. The rolling sliding wear response of conventionally processed and spray formed high chromium content cast iron at ambient and elevated temperature. Wear. 1999; 587-599. http://dx.doi.org/10.1016/ S0043-1648(99)00053-8

16. Pariona MM, Bolfarini C, Dos Santos RJ and Kiminami CS. Application of mathematical simulation and the factorial design method to the optimization of the atomization stage in the spray forming of a $\mathrm{Cu}-6 \% \mathrm{Zn}$ alloy. Journal of Materials Processing Technology. 2000; 102:221-229. http://dx.doi.org/10.1016/ S0924-0136(00)00482-9

17. Kondo K, Ueda M, Ogawa K, Amaya H, Hirata H, Takabe H et. al. Alloy design of super $13 \mathrm{Cr}$ martensitic stainless steel (development of super $13 \mathrm{Cr}$ martensitic stainless steel for line pipe-1). Proceedings of Supermartensitic Stainless Steels '99-Brussels. 1999; 11-18.

18. Tabrett CP, Sare IR and Ghomashchi MR. Microstructureproperty relationships in high chromium white iron alloys. International Materials Reviews. 1996; 41(2):59-82. http:// dx.doi.org/10.1179/095066096790326075

19. Fulcher JK, Kosel TH and Fiore NF. The effect of carbide volume fraction on the low stress abrasion resistance of high Cr-Mo white cast irons. Wear. 1983; 84(3):313-325. http:// dx.doi.org/10.1016/0043-1648(83)90272-7 